\title{
COTIDIANO E DANÇA NA PERIFERIA: REFLEXÕES PARA UMA PRÁTICA EDUCATIVA*
}

\author{
Thais Gomes Ferraz**
}

\section{RESUMO}

O estudo envolve uma pesquisa na comunidade periférica Shangri-Lá, município de Goiânia, onde foram efetuadas intervenções, observações e entrevistas com crianças e mães participantes de um projeto de educação ambiental. Embasados no referencial teórico de Agnes Heller e Newton Duarte, procuramos identificar e discutir o cotidiano e os preconceitos referentes à dança oriundos na comunidade, com o intuito de promover reflexões pertinentes à prática educativa. Neste sentido, a construção de comportamentos e pensamentos com respeito à dança é analisada em processo de relações com diferentes meios e instituições.

PALAVRAS-CHAVE: Cotidiano - Preconceito - Dança - Educação.

\section{INTRODUÇÃO}

$\mathrm{O}$

s precipitados pensamentos e as ações espontâneas, imediatistas e não refletidas que dominam o cotidiano orientam relações sociais baseadas em preconceitos. Ousamos assim refletir um pouco, mesmo que de forma incipiente, sobre a vida cotidiana e os preconceitos, apesar de ser este um tema complexo.

Heller (1970) aponta que o sistema de preconceitos é provocado pelas integrações sociais em que vivem os homens, e sobretudo pelas classes sociais. Convém, no entanto, ressalvar que

[...] juízos de classe típicos, ou seja, os juízos que expressam o interesse fático de uma classe (ou camada) e que se referem à práxis da classe (ou camada, ou nação) em questão, os juízos, em outras palavras, sobre cuja

* Este artigo é um recorte da pesquisa monográfica Cotidiano e dança na periferia:reflexões para uma prática educativa em 2002, sob orientação da professora doutora Lenir Miguel de Lima.

** Licenciada em Educação Física pela Universidade Federal de Goiás, Campus de Goiânia.. 
base atua essa comunidade, não são preconceitos. Quanto mais em "movimento" está uma classe, quanto maiores são suas possibilidades de uma práxis efetiva, tanto menos são preconceitos os seus juízos. A atividade política (no mais amplo sentido e expressão), a atividade que dirige o movimento e mobiliza as grandes integrações, pode ter êxito apenas quando se coloca na altura de um pensamento isento de preconceitos. (Heller, 1970, p. 50)

Em virtude de conceitos restritos ao espontaneísmo e à nãoreflexão sobre pensamentos e comportamentos, o preconceito encontra espaço para sua manifestação como verdade absoluta perante os olhos da sociedade, e os conhecimentos e idéias historicamente construídos deixam de ser utilizados a serviço da maioria dos seres humanos. Suspender esse cotidiano significa conceituar, conscientizar os seres humanos quanto à aparência dos fenômenos, para que encontrem a essência do que acontece nesta realidade (cultural, política, socioeconômica).

O compromisso de um educador, segundo Duarte (1996), não se limita "à reprodução do educando enquanto indivíduo, mas também visa à atuação desse indivíduo numa prática social, na construção de um determinado tipo de sociedade". Ora, o educador deve assumir e intervir com o intuito de transformar as condições que têm contribuído para a manutenção das desigualdades sociais.

No contexto cultural das classes sociais menos favorecidas, presenciamos problemas de preconceitos contra a manifestação da dança, o que impede o acesso a essa prática de forma consciente e sistematizada. Esse fato manifesta a reprodução de um conceito e significado restrito, acoplado aos interesses das classes dominantes.

Assim sendo, nossa pesquisa teve como eixo identificar e interpretar os preconceitos referentes à dança na comunidade periférica do Shangri-Lá, município de Goiânia, a fim de contribuir para uma prática educativa consciente e compromissada com as reais necessidades dos educandos envolvidos. Esperamos ainda que ela ofereça reflexões tanto para educadores que trabalham a dança quanto para aqueles que sentem receio de socializar uma manifestação cultural tão ampla de possibilidades na formação humana.

Nesta investigação, do tipo qualitativa e baseada no referencial teórico-metodológico de Triviños, destacam-se as seguintes carac- 
terísticas: a) a importância do meio social, identificado como uma realidade muito ampla e complexa; b) a descrição, que intenta captar não só a aparência do fenômeno, como também a sua essência; c) a preocupação com o processo e não simplesmente com os resultados e o produto; d) o significado; e) a análise indutiva, que apontará para a descoberta simultânea da aparência e da essência do fenômeno e avaliará um suporte teórico que atua dedutivamente.

A identificação do ambiente pesquisado foi feita através de arquivos e registros de documentos de um projeto de educação ambiental realizado no Shangri-Lá (Pezinho de Jatobá) e de entrevistas semi-estruturadas com crianças da comunidade na faixa etária entre nove e doze anos e com suas mães. Observações livres, empregadas em anotações de campo, e intervenções educativas também foram efetuadas como aspecto de natureza metodológica. Os dados identificados foram interpretados em referenciais teóricos que se articulam com as problemáticas presentes na comunidade. Dentre os referenciais pesquisados, tiveram maior ênfase a autora Agnes Heller e o pesquisador brasileiro Newton Duarte.

O setor Shangri-Lá está situado na região Norte de Goiânia, próximo ao Campus II da Universidade Federal de Goiás. Existente há quase 20 anos (Leis Municipais nos. 6.806/1989 e 6.967/1991), a região é possuidora de uma área pública municipal de 86. 757,27 $\mathrm{m}^{2}$, reservada à preservação ambiental.

Tratando-se de uma área verde, a extração ilegal de madeira, as queimadas indiscriminadas, principalmente na época da seca, e o roubo de bromélias e orquídeas têm acontecido com freqüência na região. Outro fator relevante que se constata é o temor da comunidade moradora em relação à área, visualizada por ela como um abrigo para "marginais".

Diante dessas problemáticas identificadas, há dois anos, surgiu na comunidade o projeto Pezinho de Jatobá. O projeto constitui-se de atividades de difusão e implantação da educação ambiental e envolve os moradores do Shangri-Lá e dos setores vizinhos. De caráter interdisciplinar, ele conta hoje com a participação de estudantes monitores de várias áreas de conhecimento, dentre elas Publicidade e Propaganda, Rádio e Televisão, Jornalismo, Educação Física, Artes Visuais. Envolve ainda os saberes da comunidade participante. 
Dentre os participantes da comunidade envolvida, encontramse crianças de variada faixa etária, além de pais e mães, estes em número bem menor em relação às crianças.

\section{A VIDA COTIDIANA E OS PRECONCEITOS}

Baseando-nos no referencial teórico de Agnes Heller, podemos afirmar que a vida cotidiana tem manifestado, através dos pensamentos e ações humanas, a legitimação de preconceitos.

É importante aqui explicitar o conceito de cotidiano, visto que este é de considerável relevância neste estudo. A palavra não tem, para nós, o sinônimo de dia-a-dia. Segundo Heller (1982), ${ }^{1}$ o cotidiano é aquilo que é espontâneo, natural, não refletido. Parafraseando a autora, Duarte (1996, p. 32) define:

As atividades diretamente voltadas para a reprodução do indivíduo, através da qual, indiretamente, contribuem para a reprodução da sociedade, ${ }^{2}$ são consideradas atividades cotidianas. Aquelas atividades que estão diretamente voltadas para a reprodução da sociedade, ainda que indiretamente contribuam para a reprodução do indivíduo, são consideradas não-cotidianas.

A vida cotidiana é definida assim como "o conjunto de atividades que caracterizam a reprodução dos homens singulares", ou seja, se volta diretamente para a reprodução do indivíduo. Nessa esfera de cotidiano, o ser humano está situado num contexto em que sua vida circunda o reino da necessidade direcionada para um sentido restritamente cotidiano. Seus objetivos estão voltados a um limitado nível de reprodução espontânea, o que poderá implicar uma determinada posição no interior da divisão social do trabalho.

Segundo Duarte (1996), o conceito de vida cotidiana tem ainda, dentre os seus pressupostos que devem ser levados em consideração, a diferenciação entre a reprodução do gênero humano e a reprodução dos animais. A reprodução evidenciada no caso dos animais é idêntica à reprodução dos membros singulares da espécie. Isso implica dizer que a continuidade da espécie é garantida apenas no alcançar a idade adulta e procriar. No entanto, na reprodução do gênero humano evidenciam-se não só a procriação biológica, mas também 
as atividades que reproduzem a sociedade, que reproduzem a realidade produzida historicamente pelos seres humanos.

Os seres humanos primitivos pouco se diferenciavam dos animais. Suas atividades reduziam-se somente à luta pela sobrevivência. Assim a diferença entre reprodução do indivíduo e reprodução da sociedade era praticamente inexistente.

A partir da divisão social do trabalho, da propriedade privada, a distinção entre reprodução da sociedade e reprodução do indivíduo vai se constituindo objetivamente. Esse processo coincide ainda com o surgimento da diferenciação de duas esferas de objetivação do gênero humano: a das objetivações genéricas em-si e a das objetivações genéricas para-si. Assim consideramos neste estudo que

as objetivações genéricas em-si formam a base da vida cotidiana e são constituídas pelos objetos, pela linguagem e pelos usos e costumes. As objetivações genéricas para-si formam a base dos âmbitos não cotidianos da vida social e são constituídas pela ciência, pela arte, pela filosofia, pela moral e pela política. As objetivações genéricas em-si são produzidas e reproduzidas pelos seres humanos, sem que necessariamente estes mantenham uma relação consciente com essas objetivações e com o processo de sua produção. Esse significado é dado naturalmente pelo contexto social. O mesmo não pode se dar com as objetivações genéricas para-si. Por exemplo, os homens precisam refletir sobre o significado dos conhecimentos científicos para poderem produzir e reproduzir a ciência. O processo de diferenciação entre o cotidiano e o não-cotidiano, isto é, o processo de constituição da esfera das objetivações para-si foi um grande avanço na humanização do gênero humano. (Duarte, 1996, p. 33)

É importante ainda ressaltarmos que, a princípio, não há problema algum que a formação do indivíduo tenha início no plano da individualidade para-si.

O problema existe quando durante toda sua vida o indivíduo não ultrapassa esse plano, quando sua individualidade se cristaliza enquanto individualidade em-si. Nesse caso podemos dizer que estamos diante da individualidade em-si alienada. Frisamos que não se trata de identificar o âmbito do em-si com a alienação. Esta existe quando toda a vida do indivíduo não ultrapassa esse âmbito. O âmbito em-si é necessário à vida de todos os indivíduos. Não podemos estar o tempo todo refletin- 
do sobre nossas ações. [...] Não há nenhuma razão para que julguemos necessário que a criança reflita sobre a linguagem da qual está se apropriando, assim como um adulto, em sua vida cotidiana, não reflete necessariamente sobre a linguagem que utiliza. [...] a mesma atitude espontânea não pode ocorrer quando não se tratar mais de uma atividade cotidiana, mas sim de uma atividade científica, artística, filosófica ou política. (Duarte, 1996, p. 27)

Agnes Heller (1970) considera que o homem na sua cotidianidade manifesta todos os aspectos de sua individualidade e de sua personalidade. Colocam-se "em funcionamento" todos os seus sentidos, todas as suas capacidades intelectuais, suas habilidades manipulativas, seus sentimentos, paixões, idéias e ideologias. O homem, na sua vida cotidiana, é atuante e fluidor, ativo e receptivo, no entanto não tem tempo nem possibilidade de se absorver inteiramente em nenhum desses aspectos e assim sendo não pode aguçálos em toda sua intensidade.

A vida cotidiana alcança o homem em sua particularidade. Dentre as características presentes na vida cotidiana, podemos apontar a espontaneidade, o pragmatismo (unidade de pensamento e ação), o probabilismo, a imitação, o economicismo, os precedentes, os juízos provisórios e a ultrageneralização.

Os juízos ultrageneralizadores, seja nas suas formas tradicionais ou por consequiência da experiência individual, são visualizados como juízos provisórios. Tal denominação se deve ao fato de que esse tipo de juízo

se antecipa à atividade possível e independente do confronto com a realidade; nem sempre é confirmado, sendo muitas vezes refutado no infinito processo da prática. [Porém quando é] refutado no confronto com a realidade concreta, seja por meio da ciência ou por não encontrar confirmação nas experiências de vida do indivíduo, e mesmo assim se mantém inabalável, imutável e cristalizado contra todos os argumentos da razão, não é mais um juízo provisório, mas um preconceito. (Collares, 1996, p. 25)

Podemos ressaltar que, restrito a sua vida cotidiana, o ser humano convive cercado por comportamentos e pensamentos imediatos e em-si, que por sua vez são reconhecidos e representantes do 
seu caráter de elevação do particular individual no convívio com a sociedade e nas suas necessidades de satisfação pessoal. Segundo Heller (1970, p. 48),

crer em preconceitos é cômodo porque nos protege de conflitos, porque confirma nossas ações anteriores. Mas, muitas vezes, o mecanismo é também indireto: Nossa vida, que não pode alcançar seu objetivo em sua verdadeira atividade humano-genérica, ${ }^{3}$ consegue então um 'sentido' pleno no preconceito.

$\mathrm{Na}$ formulação de julgamentos diferenciados dos seus valores, o homem promove a si próprio desconsiderando ou desconhecendo outras formas de pensamento e comportamento. Nesse sentido, predomina em si a conformidade e passividade perante situações que lhe são colocadas, diminuindo assim sua liberdade relativa perante o ato de escolha. Heller (1970, p. 45) aponta que essa conformidade

[...] converte-se em conformismo quando o indivíduo não aproveita as possibilidades de sua sociedade, caso em que as motivações da conformidade da vida cotidiana penetram nas formas não cotidianas das atividades, sobretudo nas decisões morais e políticas, fazendo com que essas percam o seu caráter de decisões individuais.

Essa questão nos remete a uma reflexão sobre as relações sociais que se manifestam na integração social entre os indivíduos. Numa sociedade capitalista, os valores, a organização e as formas de integração são postos a partir das condições materiais e subjetivas de cada indivíduo e condicionados pela estrutura social. Assim os preconceitos se legitimam partindo das próprias relações sociais que se estabelecem dentro de um sistema dividido por classes sociais em que predomina a ideologia capitalista burguesa. Heller (1970, p. 54) afirma que, com a ajuda dos preconceitos, as classes dominantes

[...] apelam à particularidade individual, que em função do seu conservadorismo, de seu comodismo e de seu conformismo, ou também por causa de interesses imediatos, é de fácil mobilização contra os interesses da sua própria integração e contra a práxis orientada no sentido do humano-genérico. 
As particularidades individuais, o espontaneísmo, o comodismo e o conformismo são características indispensáveis à manutenção do sistema capitalista e reforçadas a partir de relações sociais de dominação entre os seres humanos. O modelo de cidadão que as classes dominantes desejam remete a um estereótipo de cidadão consumidor, escravizado por necessidades imediatas e muitas vezes supérfluas. Essas "necessidades" produzidas pelo mercado garantem o sustento da divisão social do trabalho, cujo objetivo são os lucros que alcançam apenas as classes dominantes.

As classes dominadas encontram-se assim em condições desfavorecidas, visto que as oportunidades não são iguais para todos. Os segmentos e as instituições que se relacionam na vida social dos indivíduos são divididos e estabelecidos para diferentes classes sociais. As classes oprimidas, portanto, conseguem acesso apenas a um nível cultural, econômico e educacional restrito e abarrotado de limitações.

Estabelecendo uma relação consciente com as objetivações genéricas para-si (ciência, arte, filosofia, moral e política) e com as objetivações genéricas em-si, o indivíduo tem a chance de efetivar as máximas possibilidades de formação, e estas podem se transformar numa constante luta contra a reprodução limitada à inserção do trabalho. Nesse sentido consideramos que a reprodução da sociedade (o não-cotidiano) não se estabelece como mero veículo de manutenção da ordem vigente, mas como um processo contraditório que visualiza a produção do novo a partir das contradições inerentes à reprodução do já existente. Convém assim ressaltar que

a categoria do indivíduo para-si sintetiza em nossa reflexão as possibilidades máximas de desenvolvimento livre e universal da individualidade que são geradas pelas condições objetivas da sociedade atual. É importante esclarecer que se trata de um processo contraditório, pois, sendo essas condições de formação da individualidade para-si geradas numa sociedade estruturada com base nas relações sociais de dominação, essas mesmas condições são geradoras também das possibilidades de muitas e profundas formas de alienação. (Duarte, 1996, p. 28)

124 FERRAZ, T.G. Cotidiano e dança na periferia: reflexões para uma prática... 


\section{DISCUSSÃO SOBRE OS DADOS IDENTIFICADOS NA COMUNIDADE SHANGRI-LÁ}

Perante a realização de intervenções, observações e entrevistas, identificamos nessa comunidade inúmeras problemáticas. A renda das famílias do setor é muito baixa. Além disso, elas convivem com problemas de violência, fome, saúde, moradia, desemprego e até localização geográfica: o Shangri-Lá comporta uma estrutura isolada e distanciada de meios de transporte coletivo.

Em decorrência dessas problemáticas, localizamos no âmbito da dança uma visão preconceituosa, condicionada, limitada e articulada com os meios e instituições que se inserem na realidade da comunidade. Consideramos assim que esses meios e instituições estão em movimento de acordo com interesses e necessidades de adaptação deliberadas pelas classes dirigentes.

A relevância de investigar esta questão dos preconceitos em relação à dança está em despertar para questões que muitas vezes passam despercebidas. Como educadores(as) é necessário que estejamos atentos à cultura que circunda os nossos educandos, procurando manifestar uma prática educativa articulada com a realidade e as necessidades encontradas no espaço de intervenção.

Acreditamos que a dança, num contexto que acompanhe processos reflexivos, conscientes e valorizadores das objetivações genéricas para-si, não se engaja restritamente num processo cotidiano de reprodução do indivíduo e das relações sociais de dominação.

Quanto aos espaços que encontram limitações no âmbito da dança, a comunidade Shangri-Lá não é um caso isolado. Outras tantas camadas populares se encontram numa condição social desfavorecida no que tange aos níveis educacional e financeiro, os quais refletem o acesso restrito e limitado dessas camadas às modernizadas estruturas, tecnologias, bens culturais e materiais, e promovem seu isolamento e exclusão.

Desprovidas de toda a modernidade que a estrutura capitalista oferece, as classes dominadas buscam conforto nas limitadas instituições e meios de comunicação que se dispõem a acolhê-las. Sentem-se assim atraídas por instituições de apoio, como igrejas, e pela mídia (televisão e rádio), que também tem grande receptividade 
dentre elas. As classes pobres vêem na mídia o mais acessível e "envolvente" meio de comunicação presente na sua realidade, tendo seus valores fortemente influenciados por ela.

O papel das instituições e dos meios de comunicação na disseminação de valores acaba na maioria das vezes reforçando o quadro das desigualdades sociais vindas da divulgação de preconceitos direcionados para a ultrageneralização e normatização de um modelo-padrão de sociedade e indivíduo. Nesse sentido, os indivíduos que são indiferentes aos padrões de normalidade e valores impostos não são consideravelmente reconhecidos e respeitados pela maioria da população. São estigmatizados como incapazes e conseqüentemente serão excluídos e discriminados no campo do trabalho e no convívio social. Os valorizados padrões estéticos, culturais, socioeconômicos, políticos e ideológicos que se inserem no modelo de sociedade capitalista são difundidos, comercializados e segmentarizados ${ }^{5}$ para o sustento da estrutura dessa sociedade.

A diferença é classificada no âmbito sociocultural como loucura, doença ou deficiência. No contexto da dominação os indivíduos devem ser iguais e são condicionados a um perfil de comportamento e pensamento imediatista em que se evidencia a legitimação de preconceitos. Com a dominação de um grupo sobre o outro, ocorre a incessante competição a qualquer preço, para conseguir o poder e alcançar o afeto e a felicidade. Isso torna-se o "natural" da vida cotidiana. Segundo Bandeira (2002, p. 6),

[...] o preconceito pode ser uma 'máquina de guerra' presente nas relações sociais cotidianas. $\mathrm{O}$ preconceito, usualmente incorporado e acreditado, é a mola central e o reprodutor mais eficaz da discriminação e de exclusão, portanto, da violência.

Quando observamos os valores inerentes aos meios e instituições a que as camadas populares têm acesso, encontramos um contexto disseminador de ideais hegemônicos o qual impõe sobre os indivíduos modelos a serem seguidos. Saviani (1996, p. 36) aponta que,

[...] ao nascer, além de uma localização geográfica mais ou menos favorável, o homem se defronta com uma época de contornos históricos precisos, marcada pelo peso de uma tradição mais ou menos longa, com 
uma língua estruturada, costumes e crenças definidos, uma sociedade com instituições próprias, uma vida econômica peculiar e uma forma de governo ciosa de seus poderes.

Nesse sentido, Saviani define o homem como um ser situado que se desenvolve e se sustenta a partir de um contexto determinado. Deste retira os meios de sua sobrevivência, sendo levado a valorizar os elementos do meio ambiente, as instituições, as ciências, as técnicas etc.

O indivíduo direciona, portanto, suas ações e comportamentos movido por necessidades imediatas de sobrevivência, diante do modelo capitalista de sociedade em que está inserido. A situação converte o homem a uma atitude axiológica - sem que ele se dê conta - em que o valorizar se estrutura como atitude não indiferente dos indivíduos, segundo Saviani. Isso reflete um ser humano com uma multiplicidade de elementos em si mesmo que não valem nem deixam de valer; simplesmente são; estão aí. Quando se relacionam com o homem esses elementos passam a ter significado, a ter valor. $\mathrm{O}$ valor se constitui naquilo que é, sem contestações, tornando o ser humano passivo nas suas atitudes perante o ato de escolha.

Na comunidade Shangri-Lá, não houve por parte de nenhum dos entrevistados e entrevistadas qualquer oposição às aulas de dança tanto para meninas quanto para meninos. Essa questão não significa, entretanto, mudança no comportamento masculino quanto à transformação de papéis estereotipados. Afirma (Pacheco, 1999, p. 162) que

[...] a partir do momento que o homem observou que existem características em certos tipos de dança (funk, street dance, hip-hop) não o faria sofrer nenhum tipo de degradação da sua masculinidade. [...] Não considero que os homens estão libertando-se das amarras do preconceito, diria que, apesar da dança, as amarras continuam bastante fortes. $O$ fato de os homens dançarem e o rompimento de preconceitos não necessariamente configuram uma relação de reciprocidade ou de causa-efeito. Existe aí uma extrapolação que pode não proceder; ainda mais, podemos entender a participação dos homens em certas danças exatamente por elas reforçarem os estereótipos masculinos ao invés de representarem uma ruptura destes.

A aceitação da dança tanto pelos homens quanto pelas mulheres, na comunidade Shangri-Lá, vincula-se ainda a interesses 
econômicos. Isso fica evidente na fala de uma das crianças, quando indagada a respeito da questão: “[...] meninos também eles pode ser um grande dançarino, e se eles assim... for dançarino, acho que eles pode ganhá num concurso brasileiro e ficá rico" (Criança 3).

Os valores econômicos nas classes sociais desfavorecidas "tornam se prioritários, dadas as necessidades de sobrevivência, ao passo que num bairro de elite assumem prioridade os valores morais" (Saviani, 1996, p. 39).

A dança na comunidade Shangri-Lá se apresenta como atividade cotidiana justamente porque as necessidades de sobrevivência dos indivíduos se priorizam em detrimento das necessidades culturais, artísticas, políticas, morais, filosóficas, científicas. Quando uma das mães é indagada em relação ao gosto pela dança responde: “[...] eu acho bom dançar, mas a vida é corrida, tem que trabalhar e a gente larga isso pra lá" (Mãe 2).

A situação financeira dos moradores da comunidade não permite acesso a outras necessidades humanas. Em relação à dança, as mães apontam não ter tempo, dinheiro, nem meio de transporte para ir assistir a um espetáculo: "Daqui lá em cima não tem como ir. Daqui eu nem sei onde tem coisa de dança aqui. Tem que andá um quilômetro pra pegá ônibus e eu não sei onde tem coisa de dança" (Mãe 3).

A dança como atividade cotidiana na comunidade ShangriLá deve ser pensada não de forma isolada, mas em relação às condições socioeconômicas e aos diferentes meios e instituições inerentes à realidade pesquisada. Só assim contribuirá, através de pertinentes reflexões, para futuras intervenções na prática educativa. A mídia, a igreja, a escola, a ciência, o projeto Pezinho de Jatobá, que se relacionam com a formação dos indivíduos da comunidade, também não atuam e funcionam de forma isolada; relacionam-se entre si. E apresentam-se ainda na maioria das vezes associadas à lógica ideológica burguesa, predominante na sociedade capitalista.

\section{A DANÇA E A MÍdIA}

As danças do dia-a-dia dos moradores do Shangri-Lá são baseadas nas músicas acompanhadas de coreografias mecanizadas e difundidas pelos meios de comunicação a que possuem acesso, como a televisão e o rádio. 
Analisando a discussão referente à vida cotidiana e os preconceitos relacionados à dança, poderíamos apontar para uma das questões mais polêmicas encontradas hoje nos espaços onde ela se manifesta: o fato de o homem negar a dança por associa-lá a uma prática voltada para o sexo feminino. Porém cabe ressaltar que se verifica também na comunidade Shangri-Lá o movimento de pensamentos e ações deliberadas pelas necessidades do acúmulo de capital promovidas pelo mercado. Ali encontramos meninos dançando o novo condicionamento colocado pela mídia: as meninas do grupo Rouge. As crianças (meninos e meninas) da comunidade Shangri-Lá adoram dançar os "passinhos" que a televisão aos domingos tem mostrado e efetivado como verdade absoluta de performance no âmbito da dança.

Os valores embutidos por trás dessas danças difundem, nas letras que as acompanham, pensamentos e comportamentos precipitados, condicionando os indivíduos a se relacionar com a sua realidade de forma passiva e alienada. Eles assumem esses valores não só ao cantar ou dançar, mas no seu próprio dia-a dia, que alcança um modelo normal e inquestionável no âmbito da vida social.

Araújo (1996) afirma que expressões artísticas como a dança têm se direcionado ao consumo simbólico e virtual de formas de movimento e são transformadas em moda e mercadoria acrítica, definindo-se como a cultura elaborada para a massa. Esta por sua vez é veiculada pela indústria cultural, que ainda

[...] tem o poder de uniformização cultural e ideológica, dando impressão de democratização social, ao reordenar elementos tanto da cultura popular quanto da cultura erudita, compondo novos conjuntos. (Araújo, 1996, p. 3)

Neste contexto que gira em função dos interesses econômicos, danças como o funk e o samba, característicos de uma cultura popular de resistência, são apropriadas e banalizadas pela mídia, recebendo um tratamento que distorce seu real significado e finalidade e manifestando-se assim de forma descontextualizada.

Nesse processo cotidiano, o preconceito se legitima através dos valores propagados pela mídia. A lógica predominante reforça 
as relações de dominação de um grupo sobre o outro, até dentro de grupos que pertencem à mesma classe social.

\section{A DANÇA E A ESCOLA}

No espaço escolar, a dança tem se manifestado predominantemente de forma a reproduzir o modelo propagado pela mídia, ou seja, não há a preocupação de estabelecer ligações entre a dança e a realidade embutida em relações sociais de dominação. Numa das entrevistas na comunidade Shangri-Lá, ao ser indagada a respeito das apresentações de dança a que teve acesso, uma criança responde: "Na escola, teve um teatro lá assim [...] aí pegava e quem ganhava ia ganhá um brinde. Dançava aquela música assim: 'um tapinha não dói'. Aquela música feia" (Criança 2).

As danças difundidas pela indústria cultural se inserem não só na escola, mas também em espaços de lazer como clubes populares, praças e parques. Estando as danças de massa em evidência em todos os espaços e formas de comunicação a que a comunidade tem acesso, é necessário que, através do acesso ao conhecimento, ao não-cotidiano, ela possa identificar e interpretar de forma consciente as determinações econômico-culturais que se consolidam no contexto em que vive. Vale lembrar que o próprio contexto tem predominantemente apresentado uma ideologia preconceituosa e excludente de doutrinação da linguagem e manipulação da informação, legitimando a falsidade do discurso hegemônico.

A educação escolar não é uma atividade cotidiana, visto que seus conteúdos são sistematizados, objetivados. Convém salientar que a reprodução de uma visão de mundo no âmbito da dança, dentro de uma instituição escolar, não poderá, por si só, impedir que se supere a alienação como processo objetivo-social enraizado nas relações de produção. Mas cabe à educação escolar um papel bastante significativo na luta pela transformação dessas relações sociais, que é justamente o papel de conduzir os indivíduos no processo de apropriação das objetivações genéricas para-si.

Quanto à reprodução de práticas corporais da sociedade, a escola e outros espaços educativos podem utilizar como possibilidade de instrumento de trabalho a mídia, a indústria cultural, como 
ponto de partida para uma intervenção educativa que proponha uma relação mediadora entre o cotidiano e o não-cotidiano. Segundo Saviani, apud Gallardo (2002, p. 113), "a escola diz respeito ao conhecimento elaborado e não ao conhecimento espontâneo, e o professor deve partir do conhecimento espontâneo do aluno para sistematizar este conhecimento".

\section{A DANÇA E A CIÊNCIA}

Podemos ainda ressaltar uma outra instituição que influencia de forma considerável a concepção de dança predominante na sociedade: a ciência. A dança, estando intimamente relacionada ao corpo, absorve reflexos e influências de concepções científicas e ideológicas associadas à lógica da condição vigente, dominante e predominante em diferentes períodos históricos. Desde a Idade Média, artistas populares no âmbito da dança e de diferentes práticas artísticas têm sido perseguidos e discriminados, por questões referentes a interesses de poder.

Nas últimas décadas do século XIX, o circo representado por artistas e personagens como anões, palhaços, bailarinas e acrobatas surgia como a encarnação do espetáculo moderno, e seu sucesso era inegável nas diferentes classes sociais. Todas, inclusive, assistiam ao mesmo espetáculo, porém em dias e horários diferenciados para a elite e as classes populares. No entanto, isso não significou o fim da perseguição e do receio sofrido pelos artistas desde a Idade Média. Os artistas circenses

traziam o corpo como espetáculo. Invertiam a ordem das coisas. Andavam com as mãos, lançavam-se ao espaço, contorciam-se e encaixavamse em potes, em cestos, imitavam bichos, vozes, produziam sons com as mais diferentes partes do corpo, cuspiam fogo, vertiam líquidos inesperados, gargalhavam, viviam em grupos. Opunham-se assim aos novos cânones do corpo acabado, perfeito, fechado, limpo e isolado que a ciência construíra, da vida fixa e disciplinada que a nova ordem exigia. (Soares, 2002, p. 25)

Os artistas circenses representavam ameaça às autoridades por se comportarem de um modo que não se enquadrava na metrificação e quantificação burguesa. Traziam ainda às classes populares uma 
visão de corpo que não se restringia aos limites das potencialidades humanas, mas trazia à tona suas inúmeras possibilidades, o ultrapassar limites, o autodesafio.

Práticas corporais como a dança se direcionam a uma perspectiva restritamente biologicista inatista. São apropriadas e valorizadas pelas classes dirigentes em função da sua utilidade e funcionalidade diante de uma estrutura que exigia um corpo adaptado fisicamente e moralmente à assunção de um novo papel na sociedade do capital. As classes dominantes, por sua vez, apresentavam um desejo nunca antes visto: o de controlar o divertimento do povo, o tempo fora do trabalho.

A funcionalidade atribuída à dança na lógica científica hegemônica se materializa na concepcão dos moradores da comunidade Shangri-Lá. Uma das entrevistadas, ao ser indagada quanto aos benefícios que a dança pode proporcionar, responde: "Eu acho que a dança, como eu falei, é pra rejuvenescer as pessoas, divertir, distrair, sair do stress" (Mãe 2). A dança entre os moradores do Shangri-lá é pensada como: "[...] um divertimento e ginástica. [...] é bom pra minha ginástica de coluna e para os ossos" (Avó 4).

Se, por um lado, a ciência possibilitou a superação do conhecimento espontâneo, irrefletido e acrítico, por outro lado, apesar de contribuir na ampliação do conhecimento humano, sob um ponto de vista metódico reducionista e restritamente biológico, acaba reduzindo esse conhecimento ao desconsiderar os seres humanos também como seres sociais. Devemos assim perguntar se o conhecimento científico predominante na sociedade circunda a favor do homem ou contra o ser humano.

\section{A DANÇA E A IGREJA}

No período da Idade Média a influência de poder do cristianismo e da nobreza foi predominante no estabelecimento dos padrões morais que a sociedade deveria absorver como verdade absoluta e incontestável.

As danças populares desde o século II foram combatidas pela Igreja, que considerava o seu conteúdo como pagão, ligado aos rituais religiosos antigos e profanos. Juntamente com a dança os 
artistas que insistiram em praticá-la foram perseguidos durante séculos não só pela Igreja, mas pela classe dominante, que, apesar de apreciar, não aceitava o divertimento do povo nas festas e nas ruas.

Na comunidade Shangri-Lá identificamos ainda a condenação da prática de dança pela Igreja. Uma das crianças entrevistadas afirmou nunca ter dançado justamente por pertencer a uma religião que não permitia a prática. Porém, mesmo condicionada a uma visão cotidiana e passiva perante o valor colocado por sua religião, a criança apresentou interesse em assistir a uma apresentação de dança: "Gostaria, né, todo mundo gosta de vê. Pode ser qualquer uma, mas boa" (Criança 2).

$\mathrm{O}$ fato de a criança ser reprimida pela sua religião ocasiona grandes prejuízos à sua formação. De um lado está a negação do conhecimento imposta pela instituição, e de outro a vida social da criança, que terá uma formação e atuação passiva perante situações inerentes à sua realidade.

Quanto ao fato de a Igreja proibir o divertimento (as danças), as mães entrevistadas mostraram indignação. Uma delas, ao ser questionada quanto à religião que proíbe a prática de dança, ressalta: "Acho que é ignorância, porque a pessoa que dança, igual eu que gosto de dançar, é por divertimento. Eu acho que não é pecado porque até nas igreja a gente faz gesto de dança" (Avó 4).

Segundo Cavalcanti (1998), Marx defende o pressuposto de que as igrejas que se dedicam às classes baixas têm um papel central na estabilidade política. Aponta ainda que nos países onde a religião dos pobres promove passividade e resignação, os regimes políticos tendem a exercer maior controle social sobre as massas e a permanecer mais tempo no poder. Assim o conteúdo de uma religião como o cristianismo pode exercer, no seu papel ideológico, grande influência na maneira como os seus fiéis percebem a sociedade e participam de suas principais instituições na política, no trabalho, na educação e na vida familiar.

Através do seguimento dos ideais e valores que lhes são impostos, os fiéis acabam reproduzindo atitudes de isolamento, desinteresse e preconceito em relação às atividades mundanas, como a arte, a política, economia e cultura, que instituições religiosas postulam como profanas e pecaminosas. 


\section{A DANÇA E O PROJETO PEZINHO DE JATOBÁ}

O projeto Pezinho de Jatobá, dentro de seus objetivos, apresenta grandes possibilidades de oferecer aos moradores da comunidade Shangri-Lá a socialização de conhecimentos que possam contribuir para o desenvolvimento de uma formação consciente perante estruturas políticas, culturais e econômicas.

A união dos moradores (crianças e adultos) lutando por objetivos em comum, o contato com atividades oferecidas por profissionais de diferentes áreas e a troca de conhecimentos entre os membros que freqüentam o projeto possibilitam uma nova visão de mundo e de relacionamentos pertinentes a um novo projeto de sociedade, diferenciado dos padrões vigentes.

Por meio da oficina de dança que ministramos para as crianças, identificamos limites que podem ser considerados e refletidos na prática educativa. Por exemplo, houve participantes que apresentaram uma certa limitação no ato de se relacionar com o corpo do outro, tendo receio de tocá-lo. Esse é um ponto de reflexão relevante para a prática educativa e para o convívio social das crianças. Basta considerar que o fato é conseqüência de uma sociedade que se relaciona pelo viés ideológico capitalista. Nesse sentido as crianças são adaptadas desde cedo a valores individualistas que limitam e condicionam relações distanciadas. $\mathrm{O}$ corpo na sociedade capitalista é um corpo que compete, é um corpo que deve superar o corpo do outro; portanto deve estar distante dos outros.

Consideramos importante que o projeto traga novas possibilidades de pensar a dança e o corpo de forma diferenciada daquela oferecida pelos padrões vigentes da ideologia dominante.

E acreditamos em ações direcionadas para a conscientização sobre a dança de massa presente na comunidade e para o suprimento das necessidades identificadas.

\section{CONSIDERAÇÕES FINAIS}

A dança, que pressupõe a celebração e a interação dos seres humanos, quando entendida de forma inconsciente, banalizada e repleta de comportamentos que consideram o outro como objeto de 
manipulação e dominação, perde seu sentido artístico questionador e libertador, tornando-se objeto de discriminação e exclusão.

$\mathrm{Na}$ prática educativa ela deve ser pensada em processo de relação com diferentes meios e instituições ligados à realidade do meio onde socializamos qualquer intervenção educativa.

Seja em um espaço formal como a escola ou informal como o projeto Pezinho de Jatobá, a dança é uma relevante possibilidade de propiciar ao indivíduo uma formação para-si. Porém, manifestando-se restritamente de forma cotidiana, como na comunidade Shangri-Lá, ela se vê privada de novas possibilidades e condicionase aos interesses de poder, historicamente construídos pela humanidade nas suas relações sociais.

Na comunidade Shangri-Lá, a dança se expressa de forma limitada - somente as danças de massa se inserem na sua realidade. Essas danças na vida cotidiana vinculam significados espontâneos, dissociados de processos reflexivos.

$\mathrm{O}$ não-questionamento quanto à cultura circundante é reflexo de uma sociedade dividida por classes, que propaga uma ideologia de resignação e passividade. Os moradores da comunidade ShangriLá possuem acesso a um conhecimento limitado, e conseqüentemente os juízos provisórios legitimam ali preconceitos referentes à dança. A condição desfavorecida da comunidade acarreta limitações educacionais, políticas, culturais e econômicas que se refletem dentro daquele contexto de sociedade capitalista em que a divisão de renda é extremamente injusta.

Queremos aqui salientar que precisamos refletir sobre nossos próprios comportamentos e pensamentos perante as relações sociais que construímos. São estes a favor do ideal social que se deseja alcançar ou contra ele? Onde e como precisamos intervir para a transformação de uma sociedade mais justa?

Não transformamos as condições vigentes sozinhos. Se, por preconceito, excluirmos pessoas de nosso convívio social e não nos permitirmos novas experiências que fujam dos padrões de normalidade evidenciados no âmbito cotidiano, estaremos negando novas possibilidades de relações sociais diferenciadas.

Porém é importante ressaltar ainda que não nos cabe fecharnos num universo individual-particular onde os comportamentos e 
ações se direcionem apenas aos interesses particulares. Precisamos olhar nos olhos de outras pessoas, tocar, sentir, questionar, indignar-nos e agir coletivamente perante situações-limite de dominação, exclusão e discriminação que se consolidam nas relações sociais construídas.

A dança e outras atividades que propõem uma leitura nãocotidiana do dia-a-dia contribuem no âmbito social, mas a partir do momento em que não se expressam de forma espontânea, desprovida de uma consciência que relacione a realidade e as práticas corporais construídas pelos seres humanos. Tomada sob esse prisma, a dança no âmbito não-cotidiano permite ao sujeito da prática social transportar as relações que se dão no universo dançado para o ambiente onde se consolidam relações sociais de dominação, com o intuito de transformá-las.

\title{
Daily Life and Dance in the Outskirts: Reflexions for an Educational Practice
}

\begin{abstract}
This study involves a research work carried out in a neighborhood named "Shangri-lá", located in the outskirts of town. In this community, we interacted, observed, and interviewed children and their mothers as they took part in an Environmental Education project. I have based my research on the theoretical works of Agnes Heller and Newton Duarte, and I try to identify and discuss daily life and prejudicial ideas about dance that exist in this community, in order to promote reflexions about educational practices. In this sense, the construction of behavioral patterns and thoughts about dance are analyzed in the process of establishing links with diffent media and institutions.
\end{abstract}

KEY WORDS: Daily Life - Prejudice - Dance - Education.

\section{Cuotidiano y Danza en la Periferia: Reflexiones para una Práctica Educativa}

\section{RESUMEN}

El estudio envuelve una investigación en la comunidad periférica shangri-lá. En esta comunidad, intervenciones, observaciones y entrevistas fueron efectuadas con niños y madres participantes de un proyecto de Educación Ambiental. Baseándose en el referencial teórico de Agnes Heller y Newton Duarte, busco identificar y discutir lo cotidiano y los prejuicios referentes a la danza oriundos en la comunidad, con el propósito de promover reflexiones pertinentes a la práctica educativa. En este sentido, la construcción de comportamientos y pensamientos referentes a la danza, son analizados en proceso de relaciones con diferentes medios e instituciones.

PALABRAS CLAVES: Cuotidiano - Prejuicio - Danza - Educación. 


\section{NOTAS}

1. Maiores detalhes: Sociologia de la vida cotidiana. Barcelona, Penísula, 1982.

2. Para Heller, a reprodução da sociedade não se reduz à reprodução das relações sociais de dominação. Segundo a autora, a reprodução da sociedade é também a reprodução das contradições que permeiam essa sociedade. Uma dessas contradições é a existente entre o fato de que, por um lado, a sociedade capitalista forma o indivíduo reduzindo-o a alguém que ocupa um lugar na divisão social do trabalho e, por outro lado, essa mesma sociedade produz, contraditoriamente, no indivíduo necessidades de ordem superior. Tais necessidades apontam para a formação da individualidade para-si, isto é, para a formação de um indivíduo que, através de uma inserção consciente nos "sujeitos coletivos"(Gramsci), mantém uma relação consciente com as objetivações genéricas para-si (ciência, arte, filosofia, moral e política).

3. A autora considera como humano-genérico motivações e interesses do ser humano para o desenvolvimento global da humanidade, ou seja, para além da individualidade do sujeito.

4. Processo em que generalizamos de forma indiscriminada atitudes e conceitos baseados na assumência de estereótipos predefinidos.

5. Segundo Ortiz (2000), a segmentarização é a passagem de uma economia que produz em massa a uma nova estratégia comercial das grandes empresas em que se enfatiza a exploração de mercados segmentados. Na atual sociedade o mercado segmentar direciona uma produção para atender diferentes grupos e classes sociais que se comunicam entre tensões, interesses e disputas. Tais interesses afastam as classes de qualquer ideal comum, construído pela razão preguiçosa.

\section{REFERÊNCIAS}

ARAÚJO, Márcia Virgínia Bezerra. Dança na escola: cultura corporal de massa, popular ou erudita? Revista Corporis, Pernambuco, jan./dez. 1996. 
BANDEIRA, Lourdes; BATISTA, Analía Soria. Preconceito e discriminação como expressões de violência. Estudos Feministas, Florianópolis, v. 10, n.1, jan. 2002.

COLLARES, Cecília A. L.; MOYSÉS, M. A. A. Preconceito no cotidiano escolar: ensino e medicalização. Campinas: Cortez; UNICAMP, 1996.

DUARTE, Newton. Educação escolar, teoria do cotidiano e a escola de Vigotsky. 3. ed. rev. e ampl. Campinas: Autores Associados, 1996.

GALLARDO, José Sérgio Pérez; SBORQUIA, Silvia Pavesi. As danças na mídia e as danças na escola.Revista Brasileira de Ciências do Esporte, Campinas, v. 23, n. 2, p. 105-118.

HELLER, Agnes. O cotidiano e a história. 3. ed. Rio de Janeiro: Paz e Terra, 1970. p. 43-110.

ORTIZ, Renato. Mundialização e cultura. 4. ed. São Paulo: Brasiliense, 2000.

PACHECO, Ana Júlia Pinto. Educação Física e dança: uma análise bibliográfica. Pensar a Prática, Goiânia: Ed. UFG, v. 2, n.1, jun./jun, 1998.

SAVIANI, Demerval. Educação: do senso comum à consciência filosófica. 12 ed. Campinas: Autores Associados, 1996. p. 35-46.

SOARES, Carmen Lúcia. Imagens da educação no corpo. 2. ed. rev. Campinas: Autores Associados, 2002.

TRIVIÑOS, Augusto N. S. Introdução à pesquisa em ciências sociais: a pesquisa qualitativa em educação. São Paulo: Atlas.

Recebido: maio de 2003 Aprovado: junho de 2003

Endereço para correspondência Thais Gomes Ferraz Rua 19-A, no 79

Setor Aeroporto Goiânia-GO. 